\title{
A Case Study of Decapitated 38 Years Old Male Corpse from Punjab (India): Image Article
}

\section{Madhu Bala* and Anika Sharma}

Department of Zoology and Environmental Sciences, Punjabi University, Patiala 147 002, Punjab, India
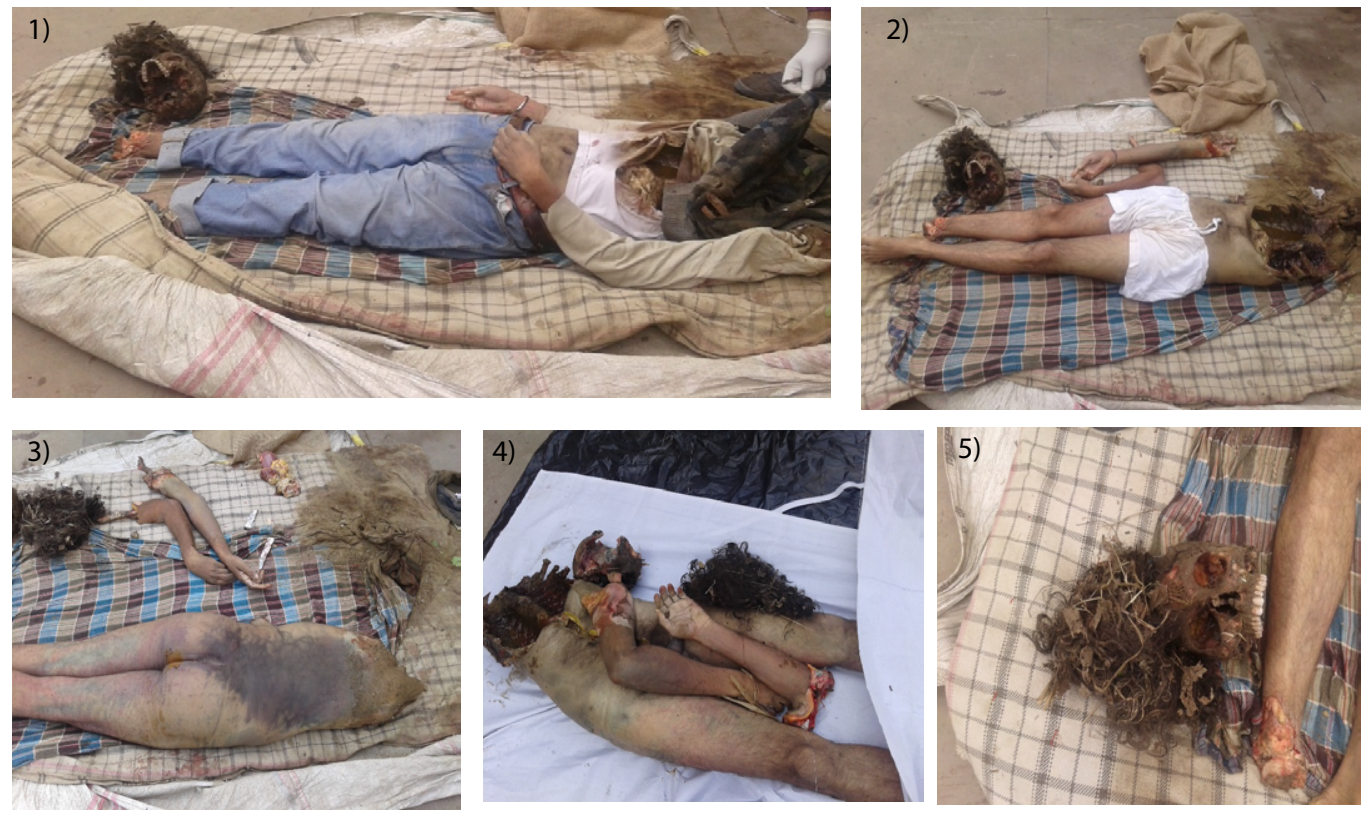

Figure 1: Decapitated male corpse with clothes found from Longowal, Punjab, India.

Figure 2: Front view of corpse.

Figure 3: Back view of corpse.

Figure 4: Skeletonized head of corpse.

Figure 5: Amputated limbs of corpse.

On $10^{\text {th }}$ January, 2015 decapitated corpse of a 38 years old male was recovered from Longowal, District Sangrur, Punjab, India. His relative reported him missing approximately 8 days prior to the discovery of the corpse. He was last seen alive on the morning of $30^{\text {th }}$ December 2014 . Autopsy revealed that he had died approximately 8-9 days ago. PMI estimated by medical examiner was based largely on the physical appearance and rate of decomposition of corpse. During autopsy, several third instar larvae of Chrysomya megacephala were collected from victim's amputated arm. The larvae were collected alive and placed immediately into $80 \%$ ethanol to identify the developmental stage. Weather data, including maximum and minimum temperature, relative humidity were obtained from Meteorological Department of Punjabi University, Patiala. Meteorological data indicate the environmental conditions to which the corpse and its associated entomofauna were exposed. Based on the temperature records for the relevant period, the number of days necessary for Chrysomy megacephala to develop from egg to larvae was calculated. The average temperature to which larvae were exposed was very less i.e. $10.6^{\circ} \mathrm{C}$ and only few larvae were collected from the corpse. Tentative PMI based on temperature data was estimated to be 9 days.

*Corresponding author: Madhu Bala, Department of Zoology and Environmental Sciences, Punjabi University, Patiala 147 002, Punjab, India, Tel: +919872129846; E-mail: madhubaladhakane@gmail.com

Received February 24, 2015; Accepted February 26, 2015; Published February 28, 2015

Citation: Bala M, Sharma A (2015) A Case Study of Decapitated 38 Years Old Male Corpse from Punjab (India): Image Article. J Forensic Res 6: i102. doi:10.4172/21577145.1000i102

Copyright: $\odot 2015$ Bala M, et al. This is an open-access article distributed under the terms of the Creative Commons Attribution License, which permits unrestricted use, distribution, and reproduction in any medium, provided the original author and source are credited. 